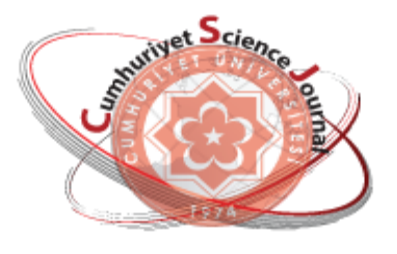

e-ISSN: $2587-246 X$

ISSN: $2587-2680$

\section{Cuculanoiy ot Seionee Journal esg}

Cumhuriyet Sci. J., Vol.40-4 (2019) 909-916

\title{
Proton Therapy Simulations by GATE in the Treatment of Non-Small Cell Lung Cancer (NSCLC)
}

\author{
Burcu ARMUTLU ${ }^{1}$ (i) , Ilknur HOŞ ${ }^{2 *}$ \\ ${ }^{1}$ Istanbul Aydın University, Graduate Education Institute, Health Physics, 34295, Istanbul, Turkey \\ ${ }^{2}$ Istanbul Aydin University, Application and Research Center For Advanced Studies, 34295, Istanbul, Turkey \\ Received: 30.10.2019; Accepted: 22.11.2019 \\ http://dx.doi.org/10.17776/csj.640079
}

\begin{abstract}
Lung cancer is one of the leading causes of cancer - related deaths. Recently, radiotherapy is being used extensively for the treatment of patients suffering from cancer. Proton therapy is a very suitable form of radiation therapy for tumors that occur in the vicinity of critical tissues such as lung, due to the unique characteristics of the protons used in the treatment. In this study, a geometry model with lung, heart, tumor and bone structures in a water phantom is modeled with the Monte Carlo simulation tool vGATE, version of 7.2. With this simulation, the accumulated dose are calculated for each organ.

Keywords: GATE, Monte Carlo, Lung cancer, Proton therapy

\section{Küçük Hücreli Olmayan Akciğer Kanseri (KHDAK) Tedavisinde GATE ile Proton Tedavi Simülasyonları}

Özet. Akciğer kanseri, kansere bağlı ölümlerde ilk sırada yer almaktadır. Günümüzde kanser hastalarını tedavi etmek amacıyla yaygın bir şekilde radyoterapi kullanılmaktadır. Proton tedavisi, tedavide kullanılan protonların benzersiz karakteristik özelliklerinden dolayı akciğer gibi kritik dokuların yakınında oluşan tümörler için oldukça uygun bir radyasyon tedavisi şeklidir. Bu çalışmada, Monte Carlo simülasyon aracı GATE (vGATE 7.2) ile bir su fantomu içerisinde akciğerler, kalp, tümör ve kemik yapıların bulunduğu bir geometri modellenmiştir. Bu benzetim ile organların aldığı dozlar hesaplanmıştır.
\end{abstract}

Anahtar Kelimeler GATE, Monte Carlo, Akciğer kanseri, Proton terapi

\section{INTRODUCTION}

According to the case records over the world in 2018, lung and breast cancer is the most common cancer. For all cancers in Turkey in 2018, a total of 210537 new cases and 116710 deaths have been reported. $34703(16.5 \%)$ of these new cases reported as lung cancer [1].

The history of radiation therapy begins in 1895 when Rontgen discovered X-ray [2]. The existence of the proton was first introduced by Ernest Rutherford in 1919 and the first cyclotron was built in 1930 by E. O. Lawrence [3]. In 1946, Robert Wilson, from Harvard University, made the first suggestion that the use of accelerated protons should be considered [3,4] for radiation therapy. In 1954, the first patient applications were reported, and in 1955 he treated the patients with protons for the first time with Tobias and his colleagues at the Lawrence Berkeley Laboratory [3,5]. Following this, clinical treatments were started at Harvard University MGH (Massachusetts General Hospital) in USA and Uppsala University in Sweden. Hospital-based proton therapy began in 1990 at Loma Linda University, and by the end of 2008, 
approximately 13,000 patients were treated [6]. Currently, there are a total of 99 particle treatment centers in the world since 1954, of which 86 are protons and 13 are carbon-ions. Furthermore, 43 treatment centers are under construction and 24 treatment centers are under planning [7].

Radiation therapy is an important component in the treatment applications for non-small cell lung cancer (NSCLC), either alone or in combination with chemotherapy and surgery [8]. The aim of radiation therapy is to protect the normal tissues around the tumor as much as possible while delivering required radiation dose to the tumor. However, radiation causes certain side effects and secondary cancer risk in healthy tissues around the tumor. Compared to photons considering accumulated the dose throughout the tissue and exit dose, protons show a maximum dose accumulation (Bragg peak) at the desired tissue depth due to their characteristic properties, followed by a sharp dose reduction with very little exit dose. This dosimetric difference of proton treatment is a good treatment option especially for lung cancer that is close to critical structures such as adjacent lung, esophagus, heart, spinal cord, main airways, vessels, as it provides an unnecessary dose reduction to critical organs [9-12]. Proton beam therapy (PBT) has also emerged as a potential solution to improve clinical outcomes such as isolated local recurrence, toxicity and life expectancy in modern photon radiation techniques in both early and locally advanced disease [8].

Recently, the popularity of Monte Carlo (MC) techniques in the field of medical physics has increased rapidly especially for proton therapy. MC simulations are important tools in the design and commissioning of clinical facilities that provide a detailed description of the beam line and distribution system and can also potentially be used to simulate the entire Proton Therapy System [13-16]. MC uses basic laws of physics to determine the probability distributions of individual interactions of photons and particles. As the number of simulated particles increases, the accuracy of predicting their dispersion increases, but the computational time is prolonged in a prohibitive manner. The dose distribution is calculated by the accumulation of ionizing events in the boxes (voxels) causing the accumulation of energy in the medium. $\mathrm{MC}$ is the most accurate method of calculating dose distribution in a patient, despite uncertainties in calculation time. Sample plans with MC simulation have shown improvements in dose calculation accuracy, particularly at the interfaces of heterogeneous tissues and in the lung where particle imbalance may occur under certain conditions [3]. Furthermore, beam data simulated with MC can be used as input data to the clinical commercial treatment planning systems [17]. This can greatly improve the commissioning efficiency of the Proton Therapy system.

GATE (OpenGATE Collab.) is an open source software developed jointly by the world's leading medical physics laboratories, which simulates medical physics using the Geant 4 code library. It supports output formats such as GATE, ROOT, ASCII, ECAT7 and LMF, which are commonly used for modeling, optimization and algorithm generation [18].

Geant4 is a toolkit that provides a comprehensive software package including the passage of particles through matter and their interactions with matter. Geant 4 can handle complex geometries efficiently and compactly and allows visualization of the geometry and particle tracks through a variety of interfaces. Its areas of application include high energy, nuclear and accelerator physics, studies in medical and space science [19-20].

There are recent studies have been performed using the Geant 4 simulation program to simulate the proton beam line and compare the simulation data with the experimental data. The first study is done by Hong Qi Tan and his friends by using the GEANT4 toolkit and MC simulations for the preliminary preparation of a new Proton Therapy Center, scheduled to open in Singapore in 2020 [21]. They have shown the energy-range comparison of the measured data the simulation for different energies and data showed compatibility is observed. A second study published by Shane Mesko and Daniel Gomez is a review of treatment options, proton doses, and outcomes for patients with non-small cell lung cancer at different stages such as early stage, locally advanced stage, relapse and postoperative NSCLC radiation [8]. This 
paper conclude that proton therapy provides higher survival, better local control and less toxicity than photon radiation therapy. A paper, by Cirrone and his friends, reported proton ranges and Bragg peaks obtained from different materials (water, aluminum, copper and PMMA) in the energy range of 10-62 $\mathrm{MeV}$ [22]. Another study done by Cirrone and friends presents the treatment of the patients with ocular melanoma lesions of different stages using an energy of $62 \mathrm{MeV}$ at the first Italian protontherapy facility called CATANA. The preliminary results were very similar to the treatment of uveal melanoma via hadrons reported in the literature, despite limited follow-up time, and showed a high percentage of tumor response with limited acute and subacute toxicity and visual outcome compared to previsions [23].

In our paper, we will report the Bragg peaks and deposited dose in the organs filled with proper materials by using vGATE. We first summarize the geometry of phantom contains lungs, heart, bones and tumor. Then Bragg peaks are shown for each organ and tumor. Later accumulated dose values are given, and results are discussed.

\section{GEOMETRY DEFINITION and SIMULATION of BEAM LINE}

All the relative results presented in this article and in the simulation of proton beam were obtained using QGSP_BERT_HP_EMY as the Reference Physics List. In this study, the vGATE7.2 version of GATE was used [18].

This study is primarily intended to demonstrate the proton beam, from the proton source defined in the simulation, dose distribution in the organs we positioned. 'Pencil Beam Scanning' (PBS) rays were used as proton source. Pencil beam scanning is a perfect and efficient proton beam delivery method for both traditional and Intensity Modulated Proton Therapy (IMPT) techniques. Its major advantage is not requiring any site-specific equipment such as scattering foils, field openings and physical range compensators, and that subsequent areas are automatically transmitted without the need to enter the treatment room [3]. The source was positioned at $130-25 \mathrm{~cm}$ inside the world volume, described in next paragraph, to suit the tumor position.

As shown schematically in Figure 1, a world volume is defined, and a water phantom is placed at the center of this volume. A bone, right and left lungs, a spherical tumor with a radius of $1 \mathrm{~cm}$ inside the left lung, an ellipsoid heart, and a second bone were identified, respectively, according to their distance from the source into the water phantom. The simulated phantom, we use, is obtained by developing a sample which makes a range-dose comparison in water using a source of pencil beam scanning of the proton beam defined in a heterogeneous phantom (water, bones, lung). The size of simulated heart inside the phantom is determined using an average adult heart shape [24]. The lung parameters described in our study are decided by using inputs from ref [25]. This reference paper aims to determine lung sizes and volume ranges using computed tomography (CT) images to contribute to the development of the body phantom for a human. Muscle was selected as tumor material and tumor is placed in the left lung at the coordinates of $0.00 .0-6.0 \mathrm{~cm}$. Tissues for each organ are defined in GATE as muscle, lung and bone materials. The heart with the material of muscle is placed in the phantom at $2.0-3.02 .0 \mathrm{~cm}$. The size and positioning of each geometry are shown in Table 1 . When the geometry formed, a schematic view is created to see the geometry. In Figure 1 left image shows lateral view (in the $\mathrm{x}$ direction), while right image represents the view from the z-axis. From the first image (left in Figure 1) one can see bone, lung, tumor within the lung, heart and second bone, respectively. When the geometry is viewed from the back, it is observed that the tumor is defined correctly in the left lung and the heart is between the two lungs along the z-axis. The source is positioned perpendicular to the phantom material (z-direction) and irradiated in this manner. $99 \mathrm{MeV}$ proton energy is used to reach the target depth and $2.14 \times 10^{7}$ particles are delivered to get the $\sim 4$ Gy dose (around one fraction out of 70 Gy [8]). 
Table 1: Dimensions and positions of simulated water phantom, organs (inside the water phantom) and tumor (inside the left lung)

\begin{tabular}{|l|l|l|}
\hline Organ & Organ Dimensions $(\mathbf{c m})(\mathbf{x}, \mathbf{y}, \mathbf{z})$ & Organ Locations $(\mathbf{c m})(\mathbf{x}, \mathbf{y}, \mathbf{z})$ \\
\hline Water Phantom & $40 \times 50 \times 40$ & 0.00 .00 .0 \\
\hline Bone 1 & $36 \times 40 \times 4$ & $0.00 .0-18.0$ \\
\hline Bone 2 & $36 \times 40 \times 4$ & 0.00 .011 .0 \\
\hline Right Lung & $11.6 \times 26.9 \times 16.9$ & $-11.00 .0-7.0$ \\
\hline Left Lung & $10 \times 26.1 \times 17.1$ & $13.00 .0-7.0$ \\
\hline Tumor & $\mathrm{r}=1$ & $0.00 .0-6.0$ \\
\hline Heart & $\mathrm{r}=6,4,3$ & $2.0-3.02 .0$ \\
\hline
\end{tabular}
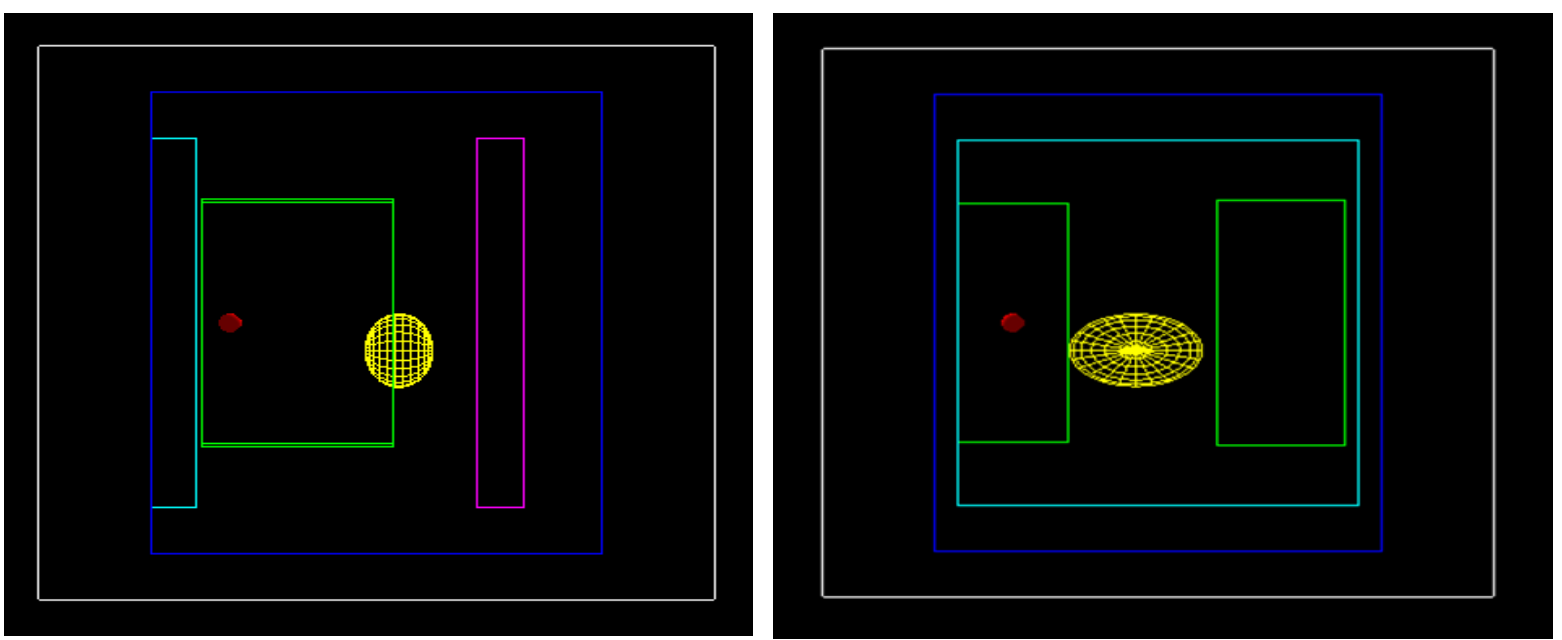

Figure 1: Schematic view of the geometry used during the simulation a) View of the simulation geometry from $270^{0}$ (lateral). b) View of the simulation geometry from $180^{\circ}$ (back). The white box is defined as world volume, blue box is the water phantom, cyan is the $1^{\text {st }}$ bone, green is the right and left lung, red is the tumor, yellow is the heart and magenta is the $2^{\text {nd }}$ bone.

\section{BRAGG PEAKS and ACCUMULATED DOSE in ORGANS}

The aim of this study is to ensure that the tumor volume receives at least $95 \%$ of the given dose, which recommended by International Commission on Radiation Units and Measurement (ICRU) and that the adjacent lungs and heart are exposed to the lowest possible dose [26]. In the simulation, the source energy was adjusted to allow the Bragg peak to peak over the tumor volume and to envelop the tumor volume. Bragg peak and dose distribution curves on the organs we defined were obtained within ROOT analysis program [27].

Figure 2 shows the dose distributions versus depth of Bragg peak for each organ obtained within the ROOT analysis program. In the simulation, when the energy is adjusted to cover the tumor volume, a peak occurs at approximately $-7.7 \mathrm{~cm}$ (distance from the negative edge of water box in z-direction) in the water phantom. In the simulation, the tumor volume was positioned at $0.00 .0-6.0 \mathrm{~cm}$ in the left lung. As seen in Figures 2a and 2c, the beam energy is adjusted and the position of the tumor is targeted. Figure $2 \mathrm{~d}$ shows that the entire volume of the tumor is exposed to dose. Dose distribution for right lung and heart decreases with depth. In the first bone, it is seen that the dose distribution with the range increases in proportion to the source. Finally, in the second bone, the dose distribution decreases deeply from the bone surface. 


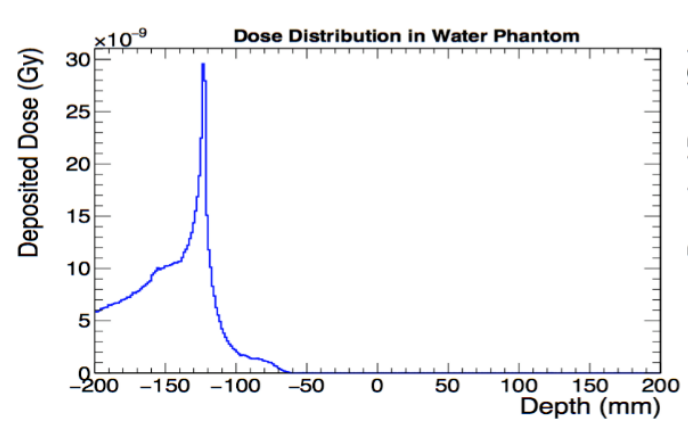

a)

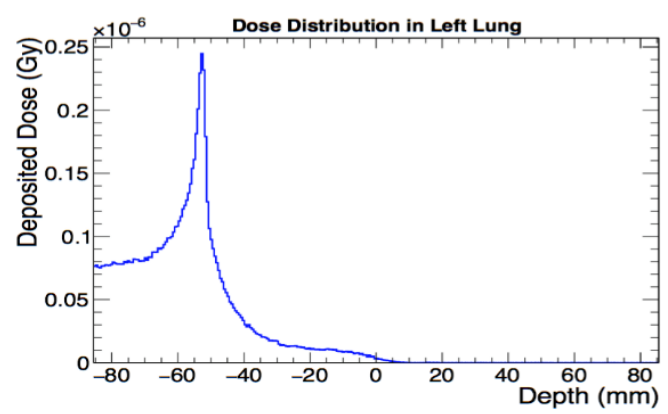

c)

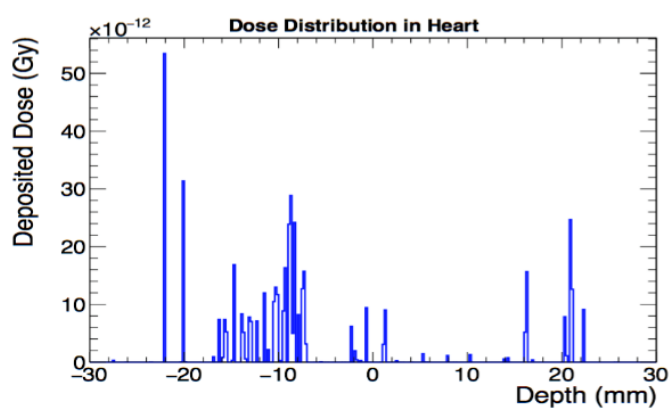

e)

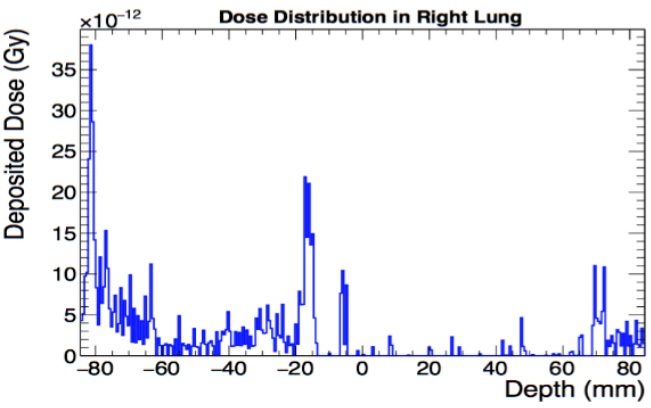

b)

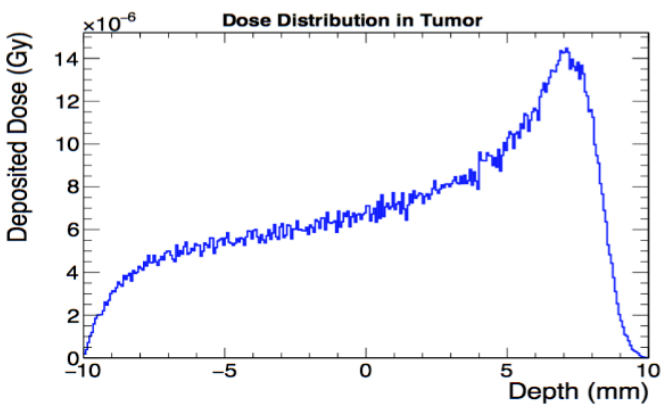

d)

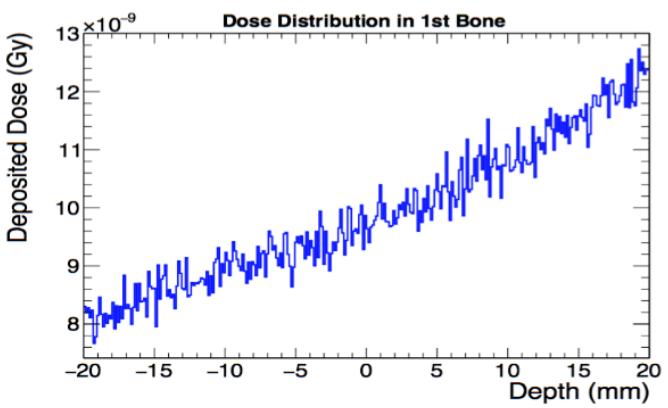

f)

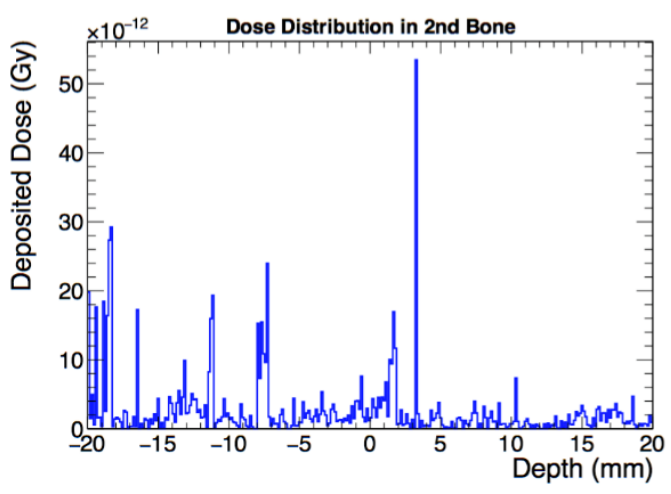

g)

Figure 2: Proton Bragg Peaks obtained by ROOT for $99 \mathrm{MeV}$ proton energy. The graph shows the stored depth in the vertical direction and the horizontal depth in the organ depth. The figure shows the dose distribution obtained for a) water phantom, b) right lung, c) left lung, d) tumor, e) heart, f) first bone, g) second bone. 
Table 2 shows the amount of dose stored in each organ in Gy. The target tissue, tumor stored 4.28614 Gy, while dose of $0.0183414 \mathrm{~Gy}$ is stored in the left lung and $2.20925 e^{-06} \mathrm{~Gy}$ is stored in heart. The acumulated dose in other organs are very low and listed in Table 2.

Table 2: Total dose accumulated in each organ and tumor

\begin{tabular}{|c|c|c|c|}
\hline Organ & Organ Volumes $\left(\mathrm{cm}^{3}\right)$ & Absorbed Dose (Gy) & Percent (\%) \\
\hline Water Box & 80.000 & 0.00155207 & $\% 0.036$ \\
\hline Bone 1 & 5760 & 0.00635112 & $\% 0.15$ \\
\hline Bone 2 & 5760 & $1.12122 e^{-06}$ & $<\% 0.01$ \\
\hline Right Lung & 5273.476 & $1.3463 e^{-06}$ & $<\% 0.01$ \\
\hline Left Lung & 4463.1 & 0.0183414 & $\% 0.43$ \\
\hline Tumor & 4.19 & 4.28614 & $\% 99.3913$ \\
\hline Heart & 301.59 & $2.20925 e^{-06}$ & $<\% 0.01$ \\
\hline Total & 101562.356 & 4.31239 & $\% 100$ \\
\hline
\end{tabular}

\section{CONCLUSION}

In this study, our aim is to ensure that the tumor volume defined in the simulation receives at least $95 \%$ of the total dose and that the adjacent lungs and heart are exposed to the lowest possible dose. In this study, a total dose of 4.31239 Gy was given to the phantom for one fraction. According to the simulation calculations, the dose in the tumor volume is $4.28614 \mathrm{~Gy}$. This shows that tumor volume takes $99.3913 \%$ of the delivered total dose. The left lung received $0.43 \%$ of the total dose, while the right lung heart received less than $0.01 \%$.

Cirrone and his colleagues used Geant 4 simulation program to illustrate proton beam line with different scatter materials and studied lateral dose distributions for proton beams at the patient position, while we used GATE simulation program to calculate accumulated dose inside the organs. Therefore, we have shown the change of Bragg peak and dose distributions without using the proton beam line and scatters defined in their study. The $99 \mathrm{MeV}$ energy used in our study is consistent with experimental peak energyrange distribution in water phantom reported in [28]. If we make a comparison of Bragg peak distributions to the ones obtained by Cirrone and colleagues, we see that the full width of the peak at half height (FWHM) is much narrower in the Bragg Peak distributions we obtained. As a result, in the absence of scattering, almost all of the delivered total dose is stored in the targeted volume and the critic organs are exposed to a very small dose, whereas a uniform dose distribution on the target tissue is not achieved since the width of the peak does not fully cover the target volume.

\section{REFERENCES}

[1] Globocan 2018 Graph production: IARC, World Health Organization. Adress: http://gco.iarc.fr/today. Retrieved September 23, 2019.

[2] Peh W.C.G., History of the discovry of x ray, part I- Rontgen and his discovery of x ray, Singapore Med. J., 36 (1995) 437-441. 
[3] Khan M.F., Gibbons J.P., (2014), Khan's The Physics of Radiation Therapy (Fifth Edition), Lippincott Williams \& Wilkins, Philadelphia, USA: LWW.com

[4] Wilson R.R., Radiological use of fast protons, Radiology, 47 (1946) 487-491.

[5] Lawrence J.H., Tobias C.A., Born J.L., Mccombs R.K., Roberts J.E., Anger H.O., Lowbeer B.V., Huggins C.B., Pituitary irradiation with high energy proton beams: a preliminary report, Cancer Res., 18-2 (1958) 121-34.

[6] Gragoudas E., Li W., Goitein M., Lane A.M., Munzenrider J.E., Egan K.M., Evidence-based estimates of outcome in patients irradiated for intraocular melanoma, Arch Ophthalmol 10-12 (2002) 1665-71.

[7] Particle Therapy Co-Operative Group (PTCOG) - An organisation for those interested in proton, light ion and heavy charged particle radiotherapy. Adress:https://www.ptcog.ch/index.php/facilitiesin-operatio. Retrieved September 30, 2019.

[8] Mesko S., Gomez D., Proton Therapy in Non-small Cell Lung Cancer, Curr. Treat. Options in Oncol., 19-12 (2018) 76. doi: https://doi.org/ 10.1007/s11864-018-0588-z.

[9] Cozzi L., Fogliata A., Lomax A., Bolsi A., A treatment planning comparison of 3D conformal therapy, intensity modulated photon therapy and proton therapy for treatment of advanced head and neck tumours, Radiother Oncol., 61-3 (2001) 287-297.

[10] Macdonald O.K., Kruse J.J., Miller J.M., Garces Y.I., Brown P.D., Miller R.C., Foote R.L., Proton beam radiotherapy versus three-dimensional conformal stereotactic body radiotherapy in primary peripheral, early-stage non-small-cell lung carcinoma: a comparative dosimetric analysis, Int $\mathbf{J}$ Radiation Oncol. Biol. Phys., 75-3 (2009) 950-958.

[11] Kadoya N., Obata Y., Kato T., Kagiya M., Nakamura T., Tomoda T., Takada T., Takayama K., Fuwa N., Dose-volume comparison of proton radiotherapy and stereotactic body radiotherapy for non-small cell lung cancer, Int J Radiat Oncol Biol Phys., 79 (2011) 1225-31.

[12] Roelofs E., Engelsman M., Rasch C., Persoon L., Quamhiyeh S., Ruysscher D.D., Verhaegen F., Pijls J.M., Lambin P., Rococo consortium, Results of a multicentric in silico clinical trial (ROCOCO): comparing radiotherapy with photons and protons for non-small cell lung cancer, $\mathrm{J}$ Thorac Oncol., 7-1 (2012) 165-76. doi: 10.1097 / JTO.0b013e31823529fc.

[13] Paganetti H., Jiang H., Lee S.Y., Kooy H.M., Accurate Monte Carlo simulations for nozzle design, commissioning and quality assurance for a proton radiation therapy facility, Med. Phys., 31-7 (2004) 2107-2118. doi: https://doi.org/10.1118/1.1762792.

[14] Van Goethem M.J., Van Der Meer R., Reist H.W., Schippers J.M., Geant4 simulations of proton beam transport through a carbon or beryllium degrader and following a beam line, Phys. Med. Biol., 7-54 (2009) 5831-5846. doi:https://doi.org/10.1088/0031-9155/54/ 19/011.

[15] Aso T., Kimura A., Tanaka S., Yoshida H., Kanematsu N., Sasaki T., Akagi T., Verification of the Dose Distributions With GEANT4 Simulation for Proton Therapy, IEEE Transactions on Nuclear Science, 52-4 (2005) 896-901. doi: https://doi.org/10. 1109/tns.2005.852697.

[16] Allison J., Amako K., Araujo H., Apotolakis J., Geant4 developments and applications, IEEE Trans.Nucl.Sci., 53-1 (2006) 270-278.

[17] Clasie B., Depauw N., Fransen M., Gom C., Panahandeh H.R., Seco J., et al.: Golden beam data for proton pencil-beam scanning. Phys. Med. Biol. 57-5 (2012). doi:https://doi.org/10.1088/ 00319155/57/5/1147.

[18] Users Guide V7.2 From GATE collaborative documentation wiki. Adress: http://www.opengatecollaboration.org/sites/default/files/GATE-UsersGuideV7.2.pdf. Retrieved September 13, 2019. 
[19] Agostinelli S., Allison J., Amako K. al, Apostolakis J., Araujo H., Arce P., Asai M., Axen D., Banerjee S., Barrand G., GEANT4 - a simulation toolkit, Nucl. instruments methods Phys. Res. Sect. A Accel. Spectrometers, Detect. Assoc. Equip., 506 (2003) 250-303.

[20] GEANT4 a simulation toolkit. Adress: https://geant4.web.cern.ch/. Retrieved: November 19, 2019.

[21] Tan H.Q., Phua J.H., Tan L., Ang K.W., Lee J., Bettiol A.A., Geant4 Simulation for Commissioning of Proton Therapy Centre, World Congress on Medical Physics and Biomedical Engineering 2018, IFMBE Proceedings, 68-1 (2018) 583-587. doi:https://doi.org/10.1007/978-981-10-9035-6_108.

[22] Cirrone G.A.P., Cuttone G., Nigro S.L., Guatelli S., Mascialino B., Pia M.G., Raffaele L., Russo G., Implementation of a New Monte Carlo GEANT4 Simulation Tool for the Development of a Proton Therapy Beam Line and Verification of the Related Dose Distributions, IEEE Transactions on Nuclear Science, 52-1 (2005) 262-265. doi:10.1109/TNS.2004.843140.

[23] Cirrone, G.A.P., Cuttone, G., D. Battaglia L., Calabbretta L., Celona F., Di R., Lojacono P., Maggiore M., Mongelli V., Nigro L.S., Piazza L.A.C., Patti V.I., Raffaele L., Re M., Rifuggiato D., Russo G.,Sabini M.G, Salamone V., Valastro L.M., A $62 \mathrm{MeV}$ Proton beam for the treatment of ocular melanoma at Laboratori Nazionali del Sud-INFN (CATANIA), IEEE Nuclear Science $\begin{array}{lllll}\text { Symposium. } & \text { Conference } & \text { Record, } & 5 & \text { (2003) 3658-3662. }\end{array}$ doi:https://doi.org/10.1109/NSSMIC.2003.1352701.

[24] Gray H., Gray's Anatom, 39th ed. Londo: Churchill; (2005) 997-1003.

[25] Kramer G.H., Capello K., Bearrs B., Lauzon A., Normandeau L., Linear dimensions and volumes of human lungs obtained from CT images. Health Phys., $102-4$ (2012) 378-83. doi:10.1097/HP.0b013e31823a13f1.

[26] International Commission on Radiation Units and Measurement)(ICRU). Adress:https://icru.org/. Retrieved September 13, 2019.

[27] Rene B. and Fons R., ROOT An Object Oriented Data Analysis Framework, Proceedings AIHENP'96 Workshop, Lausanne, Nucl. Inst. \& Meth. in Phys. Res. A., 389 (1997) 81-86.

[28] Rinecker Proton Therapy Center Third Annual Report Establishing Proton Cancer Therapy in Europe. Adress: https://www.rptc.de/en/information/latest-news/progress-reports/news-progressreports-detail/rinecker-proton-therapy-center-third-annual-report-establishing-proton-cancertherapy-in-europe.html. Retrieved September 10 (2019). 